\title{
Meditação Ativa de Osho à luz dos Cuidados Integrativos: relato de experiência empírica
}

\author{
Osho's Active Meditation in the light of the Integrative \\ Care: empirical experience report
}

\author{
Cíntia Bloise Hochmüller ${ }^{1}$, Sissy Veloso Fontes ${ }^{2}$
}

\begin{abstract}
1.Terapeuta Corporal, Arte-Educadora, Especialização em Teorias e Técnicas para Cuidados Integrativos pela UNIFESP, São Paulo-SP, Brasil.

2.Fisioterapeuta, Psicóloga, Professora de Educação Física, Doutora em Ciências/Neurologia; Professora Afiliada do Departamento de Neurologia e Neurocirurgia da UNIFESP, São Paulo-SP, Brasil.
\end{abstract}

\begin{abstract}
Resumo
Introdução. a Meditação Ativa de Osho é uma junção da milenar sabedoria do oriente com conhecimentos de algumas práticas terapêuticas do ocidente e, está intimamente ligada ao nosso modo de vida contemporâneo, compreendendo o homem na sua multidimensionalidade. A disseminação desta prática meditativa pode elevar e promover o nível de saúde de forma integral dos praticantes e refletir em modo de viver mais sensível e conectado consigo mesmo, com o outro e com o meio ambiente, como propõe a epistemologia dos Cuidados Integrativos. Objetivo. apresentar relato de experiência sobre os efeitos da Meditação Ativa de Osho nas dimensões físico/energético, mental, emocional e espiritual de praticantes regulares, e discutir como a Meditação Ativa pode ser considerada um caminho autêntico de Cuidado Integrativo, com base na revisão de literatura. Método. pesquisa exploratória de caráter qualitativo, retrospectivo baseada em questionário aplicado de opinião de praticantes regular da Meditação Ativa de Osho; revisão bibliográfica de artigos científicos na base de dados Medline (Medlars Online), via Pubmed e Google Acadêmico. Resultados. a Meditação Ativa de Osho está ancorada na visão salutogênica congruente com o paradigma em saúde da epistemologia dos Cuidados Integrativos. Através da sua abordagem sistêmica e metodologia vivencial, contribuiu para potencializar 0 autoconhecimento, o aumento e a promoção de saúde nos âmbitos físico/energético, mental, emocional e espiritual. Conclusão. Podemos inferir efeitos positivos e grande contribuição desta prática meditativa como agente mobilizador de "transformação do ser humano". A aplicação da Meditação Ativa de Osho é essencialmente integrativa podendo ser considerada um autêntico Cuidado Integrativo.
\end{abstract}

Unitermos. Meditação Ativa; Osho; Saúde, Autoconhecimento, Espiritualidade, Cuidados Integrativos

\footnotetext{
Abstract

Introduction. Osho Active Meditation is a junction of the ancient wisdom of the East with knowledge of Western therapeutic practices and is closely linked to our contemporary model of life, comprising man in his multidimensionality. The dissemination of this meditative practice can raise and promote the integrally health's level of practitioners and reflects in a more sensitive way of life, connected with oneself, with others and with the environment. Objective. To report on experiences on the possible effects of Osho Active Meditation on the physical / energetic, mental, emotional and spiritual aspects of regular practitioners, and to discuss how Active Meditation can be considered an authentic path of Integrative Care based on literature review. Method. Qualitative, retrospective exploratory research applied to a questionnaire applied to the opinions of regular practitioners of Osho Active Meditation; Bibliographical review of scientific articles in the Medline database (Medlars Online), via Pubmed and Google Scholar. Results. Osho Active Meditation is anchored in the salutogenic view congruent with the health paradigmof the Integrative Care epistemology. Through its systemic and methodological experiential approach, it contributed to enhance selfknowledge, increase and promote health in the physical / energetic, mental, emotional and spiritual areas. Conclusion. We can infer positive effects and major contributions of this meditative practice as a mobilizing agent of transformation of being. The application of Osho
} 
Active Meditation is an integrative essential that can be considered a genuine integrative care.

Keywords. Active meditation; Osho; Health, Self-knowledge, Spirituality, Integrative Care

Trabalho realizado no Curso de Especialização em Teorias e Técnicas para Cuidados Integrativos da Disciplina de Neurologia Clínica do Departamento de Neurologia e Neurocirurgia da Universidade Federal de São Paulo/ Escola Paulista de Medicina, São Paulo-SP, Brasil.

Conflito de interesse: não

Recebido em: 01/08/2017

Aceito em: $1 / 12 / 2017$

Endereço para correspondência: Cíntia B Hochmüller. R. Ministro Godoi 637/51, CEP:05015-000, São Paulo-SP, Brasil. E-mail: dayitagyan@gmail.com

\section{INTRODUÇÃO}

A meditação é uma prática milenar, descrita e relatada durante a história da civilização por diferentes culturas, principalmente a hindu e a chinesa ${ }^{1}$. 0 interesse do público leigo sobre meditação tem aumentado nos últimos anos, bem como, a produção de pesquisas científicas sobre 0 tema. Porém, abordar o tema meditação pode remeter a ideia equivocada de que, a prática pode ser restrita a somente estar completamente tranquilo e sereno, entoando mantras, ficar sentado em posição difícil para atingir o silêncio, como por exemplo, na postura de "Lótus", necessidade de ser realizada, concomitantemente alguma prática religiosa, ou ainda, ser apenas uma tentativa de "parar a mente" e, desfrutar de alguns momentos de paz e relaxamento. Esta perspectiva inferiu à medição uma conotação inadequada, muito séria, e difícil de compreender ${ }^{2}$.

Neste ponto que o Mestre indiano Osho, na década de 60 teve a sabedoria de integrar a milenar experiência do caminho do silêncio e da espiritualidade do oriente, à sabedoria do caminho do conhecimento da psicologia 
ocidental, criando a chamada "Meditação Ativa". Uma verdadeira integração de várias culturas e saberes ${ }^{3}$.

Podemos entender a meditação enquanto um estado ou técnica. Enquanto estado, em sânscrito meditação significa um estado de 'não-mente', um estado de 'nãopensamento', que é exatamente o oposto da contemplação. Contemplação não é a palavra certa para traduzi-la. Dhyana é uma daquelas palavras que não podem ser traduzidas ${ }^{4}$. Osho desmistifica o lugar de que meditação é concentração ou qualquer outra coisa que o ser humano já não possua. Reforça, também, que a meditação deve ser compreendida como parte da vida e não como algo separado. Que, uma vez experimentado o estado meditativo, é possível estendê-lo e desfrutá-lo no dia a $\mathrm{dia}^{2}$.

Para Osho (1931-1990), meditação é a natureza do indivíduo. É 'simplesmente ser'. 'Não fazer nada'. É estar deleitado na presença plena sem nenhum objetivo, perceptivo ao mundo interior e exterior. 'Estar presente sem nenhum desejo', completamente relaxado no "aquiagora", este é o verdadeiro estado da meditação ${ }^{2}$. Para que seja possível atingir o estado meditativo é necessário a escolha de um caminho, que chamaremos de "técnica". Operacionalmente, a meditação pode ser um procedimento que se utiliza de alguma técnica específica (claramente definida), envolvendo o relaxamento muscular e o relaxamento da lógica durante o processo; sendo obrigatoriamente um estado auto induzido, que utiliza o 
artifício da âncora, como por exemplo, a respiração consciente ${ }^{5}$. Os objetivos e as técnicas da meditação variam. Podendo servir como um meio de relaxamento do dia a dia, como técnica para desenvolver a disciplina mental e, também ser uma forma, segundo algumas culturas antigas, de obter-se insights sobre a 'essência da natureza humana' ou a 'comunicação com Deus'6 .

A maioria dos métodos meditativos foram desenvolvidos no Oriente e, consequentemente, congruente aos pensamentos dos povos orientais, arraigados aos costumes milenares. Não levaram, portanto, em consideração as características do homem ocidental com sua mente veloz, perturbada e angustiada pela competitividade e necessidades do mundo contemporâneo ${ }^{3}$. Observando as tendências do mundo contemporâneo, os hábitos e os desafios do homem moderno, tanto no oriente como no ocidente, a paciência e o estado de silêncio impostos, estavam relacionados, muitas vezes, há ações opressoras e, podiam levar a repressão de 'sentimentos latentes' que impediam a mente de silenciar e ou levavam a estado de adoecimento, o que fez com que as técnicas de meditação ativa pudessem ser uma alternativa promissora para os ocidentais e, também necessárias à mente oriental na contemporaneidade ${ }^{3}$.

Osho revolucionou os conceitos tradicionais existentes na época sobre meditação, trazendo a perspectiva do prazer, da alegria, do 'não esforço', onde as técnicas são uma preparação para o silêncio e um caminho para a 
transcendência. Elas possibilitam o resgate da percepção, despertando a possibilidade de reconexão com o êxtase da vida².

Todos nós nascemos em profundo estado de meditação, mas no decorrer da vida vamos aprendendo a reprimir, 'quem realmente somos' para sermos aceitos ${ }^{2}$. Para resgatar este 'estado meditativo perdido', Osho, então propôs um olhar contemporâneo sobre os 112 métodos de meditação descritos no Vigyan Bhairav Tantra - técnicas para ir além da consciência, "descritas" por Shiva e, criou suas próprias técnicas. A "mente", para qual Shiva escreveu os 112 métodos de meditação, não existe mais. Estes métodos foram descobertos há dez mil anos e, é a essência de todos os métodos de meditação existentes ${ }^{7}$.

As técnicas de Meditação Ativa são variadas, envolvem movimentos corporais por vezes intensos, de caráter físico vigoroso que podem levar a 'catarse' - a livre expressão de sentimentos, outras com movimentos corporais ou atitudes suaves, que levam a quietude, visam, primeiramente aliviar as tensões corporais e desbloquear o "caminho emocional" que está impedindo o contato com a "essência" do estado meditativo, que é a natureza do ser humano ${ }^{2}$. As técnicas trabalham com o contraste de movimento e inatividade, promovendo primeiramente movimentos, às vezes intensos, pelas ações corporais, danças, respirações "caóticas" que fazem um contraponto aos estágios finais, que são de relaxamento e silêncio. Com o corpo-mente relaxado, fica mais fácil ampliar a percepção do "aqui- 
agora" e atingir o estado meditativo. Os três elementos essenciais da prática são: relaxamento, a observação e o não-julgamento ${ }^{2}$.

Nesta prática meditativa o corpo é tido como um "veículo sagrado", onde é possível acessarmos vários campos energéticos e encontrarmos um caminho de auto cura $^{8}$. Segundo Osho, as ciências da saúde sabem que 'o corpo possui muito mais sabedoria que nós'. Os médicos mais notáveis disseram que nós não podemos curar o corpo; o corpo cura a si próprio - nós podemos auxiliá-10 ${ }^{8}$.

Em uma palestra dada para a Associação Médica em Ahmedabad, Gujarat, Índia, Osho falou sobre a importância da meditação, das práticas complementares na saúde e da urgência da medicina reencontrar a ponte com a espiritualidade, e, definitivamente reconhecer que o corpo é a parte visível da alma, e a alma a parte invisível do corpo, que são uma unidade orgânica ${ }^{8}$. Abordou também, a importância de trabalhar de modo a integrar a alopatia às práticas milenares, como a meditação no âmbito da saúde, pois, muito provavelmente são os profissionais da saúde que irão se tornar a primeira ponte entre a religião e a ciência ${ }^{8}$. A meditação ativa é uma porta para o autoconhecimento que enxerga o ser humano na sua forma multidimensional e, pode auxiliar na sua integração. É uma porta de reconexão, de "religare" através do resgate da alegria. Uma possibilidade verdadeira para um caminho profundo de autoconhecimento e "despertar espiritual"9. A 
harmonia interior, que é a fonte da saúde, pode ser encontrada com a meditação ${ }^{8}$.

'É preciso voltar à origem, à essência'. E, essa reconexão, para Osho só é possível através da meditação, que é o estado da fonte, da face original ${ }^{10}$. Para entender a saúde é necessário entender a vida. E, o primeiro princípio da vida é a meditação. 'A meditação permitirá entrar na imortalidade, na eternidade, na sua divindade ${ }^{8}$.

Para Goleman, no oriente é de consenso, tanto do ponto de vista científico como religioso, que a meditação é a principal forma para transformar qualidades ideais em traços estáveis; e, foi essa inferência que assentiu a chegada da meditação no meio científico ocidental ${ }^{11}$.

A meditação ativa tem sido uma ferramenta muito útil para a melhora da saúde, como por exemplo, auxílio na redução de várias psicopatologias, como comportamento agressivo, estados de ansiedade e depressão $0^{12}$ e, pode ser recomendada para melhorar o estresse e os distúrbios físicos e mentais relacionados ao estresse ${ }^{13}$.

O presente trabalho propõe apresentar relato de experiências, sobre os possíveis efeitos da Meditação Ativa de Osho nas dimensões físico/energético, mental, emocional e espiritual de praticantes regulares, e discutir com base na revisão de literatura, como a Meditação Ativa pode ser considerada um caminho autêntico de Cuidado Integrativo. 


\section{MÉTODO}

Este estudo é uma pesquisa exploratória de caráter qualitativo, retrospectivo, com base em pesquisa de opinião (resposta, por escrito às duas perguntas semidirigidas e uma pergunta aberta, elaboradas pela autora do estudo) de praticantes regular, da Meditação Ativa de Osho; e, na experiência empírica da autora do estudo como praticante há 21 anos de meditação ativa, facilitadora e diretora da "Escola de Meditação Osho" que é um núcleo de estudo ensino e formação especializado nas Meditações Ativas de Osho, na cidade de São Paulo, capital paulistana.

\section{Amostra}

Participaram do estudo 80 (oitenta) alunos regulares da escola, com no mínimo 8 (oito) semanas de prática de meditação ativa, que fizeram a inscrição espontaneamente para a iniciação nas técnicas de meditação ativa de Osho, e assinaram o Termo de Consentimento Livre e Esclarecido para participação do Estudo.

\section{Procedimento}

O programa do Curso de Iniciação à Meditação Ativa consistiu de 8 (oito) encontros presenciais em grupo, durante 8 (oito) semanas consecutivas, onde foram facilitadas 8 (oito) técnicas principais de meditação ativa (Dinâmica, Kundalini, Gibberish, Mandala, Chakra Breathing, Nadabrahma, Nataraj e Heart Chakra), por uma única e mesma facilitadora de meditação, com uma hora de 
duração cada encontro. A cada semana, no encontro foi realizado a aprendizagem e a prática da técnica que deveria ser realizada em casa, no mínimo mais três vezes na semana, até o próximo encontro semanal. A metodologia utilizada é teórico-vivencial com ênfase na prática. Ao final deste período de oito semanas de prática de Meditação Ativa de Osho foi realizada a coleta dos dados - aplicação do questionário contendo as seguintes perguntas: Pergunta 1 (P1): Como foi para você a experiência da Escola de Meditação? Pergunta 2 (P2): Você destacaria algum efeito da meditação ativa, em sua vida? Pergunta 3 (P3): Há algo mais que gostaria de relatar sobre a experiência da meditação ativa?

\section{Análise}

Considerando o estudo qualitativo, os conteúdos das entrevistas foram analisados, selecionados e agrupados em categorias temáticas principais (físico/energético, mental, emocional e espiritual). Foi utilizado o método de "análise de conteúdo" seguindo as proposições de Bardin $(1977)^{14}$, que aplicou as técnicas na investigação psicossociológica e no estudo das comunicações de massa. A partir das quatro categorias temáticas principais, descritas acima, derivaramse outras três categorias de interface com os pilares pedagógicos dos Cuidados Integrativos: autoconhecimento, alteridade e transdisciplinaridade. Os achados foram discutidos com base na revisão da literatura, sobre os efeitos da meditação ativa nos cuidados com a saúde, para 
isso, foram pesquisados artigos científicos nas bases de dados, com as respectivas palavras chave, que nos conduziram aos seguintes achados:

- Na MEDLINE (Medlars Online), via Pubmed com a palavra chave: "active meditation" surgiram 151 artigos científicos, mas, sobre a Meditação Ativa de Osho, especificamente nos cuidados com a saúde, foi encontrado apenas um artigo relevante intitulado: "Effect of Dynamic Meditation on Mental Health" (2015). Na mesma plataforma, utilizando a palavra chave: "dynamics meditation" foi encontrado mais uma publicação do mesmo autor, com o título: "Effects of dynamic meditation on anxiety", publicado no Indian Journal of Health (2014). Na busca manual das referências desses 2 (dois) artigos, encontramos, mais um artigo: "Effects of Seven-Day Osho Dynamic Study: A Pilot Study", de Avni Vyas (2007). Também foram utilizadas, para pesquisa nessa base de dados, as palavras chave: "Osho" e "Rajneesh", mas nenhum artigo foi encontrado com esses unitermos.

- No Google acadêmico foram utilizadas as palavras chaves "meditação ativa de Osho" e, foram encontradas 112 citações, dentre elas artigos científicos, livros texto, monografias, dissertações e teses. Sendo que desses trabalhos, com exceção dos 3 (três) encontrados na base de dados MEDLINE, que também aparecem nos achados dessa base, nenhum apresenta a Meditação Ativa de Osho como tema principal da pesquisa e, sim a utilizam como 
referência para outras práticas como: yoga, teatro, dança, arteterapia etc.

Considerando, as poucas pesquisas encontradas, nas bases de dados pesquisadas, com relação ao tema deste estudo, nas discussões dos achados incluir-se-á, como referencial, principalmente livros textos de Osho, a fim de contextualizar os efeitos da Meditação Ativa, a partir do relato das experiências do próprio fundador do método.

\section{RESULTADOS}

Total de 80 (oitenta) alunos, com idade mínima de 20 anos e máxima de 69 anos; sendo que, 53 indivíduos (66\%) eram do sexo feminino. A escolaridade variou de ensino fundamental completo à pós-graduado, nível doutorado. As profissões também foram variadas.

A Tabulação resumida de respostas relevantes dos alunos das categorias temáticas principais: "FísicoEnergético, Mental, Emocional e Espiritual", é apresentada no Quadro 1.

\section{DISCUSSÃO}

Observou-se, através dos relatos das experiências vivenciadas, que a Meditação Ativa de Osho proporcionou aumento da percepção subjetiva de saúde de modo integral, em todas as categorias temáticas estudadas. 
Quadro 1. Trechos de respostas dos entrevistados, segundo a categoria temática.

\begin{tabular}{|c|c|}
\hline Categoria temática & trechos das respostas da pesquisa de opinião \\
\hline Físico/Energético & $\begin{array}{l}{[\ldots] \text { "acessar e manter um nível de energia e disposição física }} \\
\text { mais elevado". } \\
{[\ldots] \text { "consegui aliviar tensões acumuladas no meu corpo". }} \\
{[\ldots] \text { "meu corpo está mais leve, livre, a energia circula, está viva". }} \\
{[\ldots] \text { "a respiração fica naturalmente mais livre. }} \\
{[\ldots] \text { "percebi diminuição das dores no corpo" }} \\
{[\ldots] \text { "sinto que estou conectada com meu corpo" }}\end{array}$ \\
\hline Mental & $\begin{array}{l}{[\ldots] \text { "mais concentração, leveza, discernimento para tomar }} \\
\text { decisões". } \\
{[\ldots] \text { "o melhor jeito de esvaziar a minha mente". }} \\
{[\ldots] \text { "percebi que a mente não sou eu. E, isso é libertador!" }} \\
{[\ldots] \text { "parei de tomar antidepressivo." }} \\
{[\ldots] \text { "há mais de dez anos que tenho insônia. Agora consigo }} \\
\text { dormir sem nenhum problema". } \\
{[\ldots] \text { "facilita acalmar a mente e sentir a não-mente de uma forma }} \\
\text { bem mais fácil do que apenas sentar e meditar (zen)." } \\
{[\ldots] \text { "me tornei muito presente, muito sensível, no aqui e agora." }} \\
{[\ldots] \text { "um contato maior com minha consciência." }}\end{array}$ \\
\hline Emocional & $\begin{array}{l}\text { [...] "diminuição da ansiedade, mais serenidade, tranquilidade, } \\
\text { leveza". } \\
\text { [...] "foi ótimo para perceber o quanto me importava com a } \\
\text { opinião de outras pessoas". } \\
{[\ldots] \text { "leveza. Mais tranquilidade para receber mensagens/situações }} \\
\text { positivas e negativas". } \\
\text { [...] "consegui coragem para agir da maneira que bem entendo, } \\
\text { sem me preocupar com o que o outro vai pensar". } \\
\text { [...] "consigo hoje ser amoroso, ter compaixão pelo próximo, } \\
\text { enxergar o lado bom de cada um e, principalmente não julgar". } \\
{[\ldots] \text { "mais calma, menos intempestiva, mais tranquilidade na }} \\
\text { tomada de decisões, mais segurança, mais alegre". } \\
{[\ldots] \text { "jornada de muita alegria e autoconhecimento. São ciclos de }} \\
\text { altos e baixos que, no final eu aprendo a me entender melhor". } \\
{[\ldots] \text { "me sinto mais tolerante e paciente com as pessoas e com os }} \\
\text { problemas da vida". } \\
{[\ldots] \text { "hoje me conheço mais, me julgo menos e me permito mais. }} \\
{[\ldots] \text { "experimento minhas emoções - a expressão e o }} \\
\text { reconhecimento dessas". } \\
{[\ldots] \text { "destaco os sentimentos de alegria e prazer que em mim }} \\
\text { reverberaram". } \\
{[\ldots] \text { "senti um sentimento de autonomia e liberdade bem grande. }} \\
\text { Não só no corpo, mas na minha maneira de me relacionar com o } \\
\text { mundo e com as pessoas". } \\
{[\ldots] \text { "estou mais confiante. Eu tenho força. Tenho amor verdadeiro }} \\
\text { transbordando do meu coração". } \\
{[\ldots] \text { "benefício de bem-estar, de ficar plena, ou seja, bem comigo }} \\
\text { mesma". } \\
{[\ldots] \text { "maior equilíbrio e diminuição da ansiedade". }} \\
{[\ldots] \text { "aprendendo a parar de me identificar com as emoções e com }} \\
\text { os humores". } \\
{[\ldots] \text { "conectada com meus sentimentos e com minhas emoções". }} \\
{[\ldots] \text { "desbloqueio de emoções". }} \\
{[\ldots] \text { "descobri que existe muita coisa bonita dentro de mim". }} \\
{[\ldots] \text { "não me identificar com os sentimentos e conseguir olhar "de }} \\
\text { fora". } \\
{[\ldots] \text { "me fez sentir mais viva". }}\end{array}$ \\
\hline
\end{tabular}


Quadro 1 (cont). Trechos de respostas dos entrevistados, segundo a categoria temática.

\begin{tabular}{|c|c|}
\hline Categoria temática & trechos das respostas da pesquisa de opinião \\
\hline Espiritual & 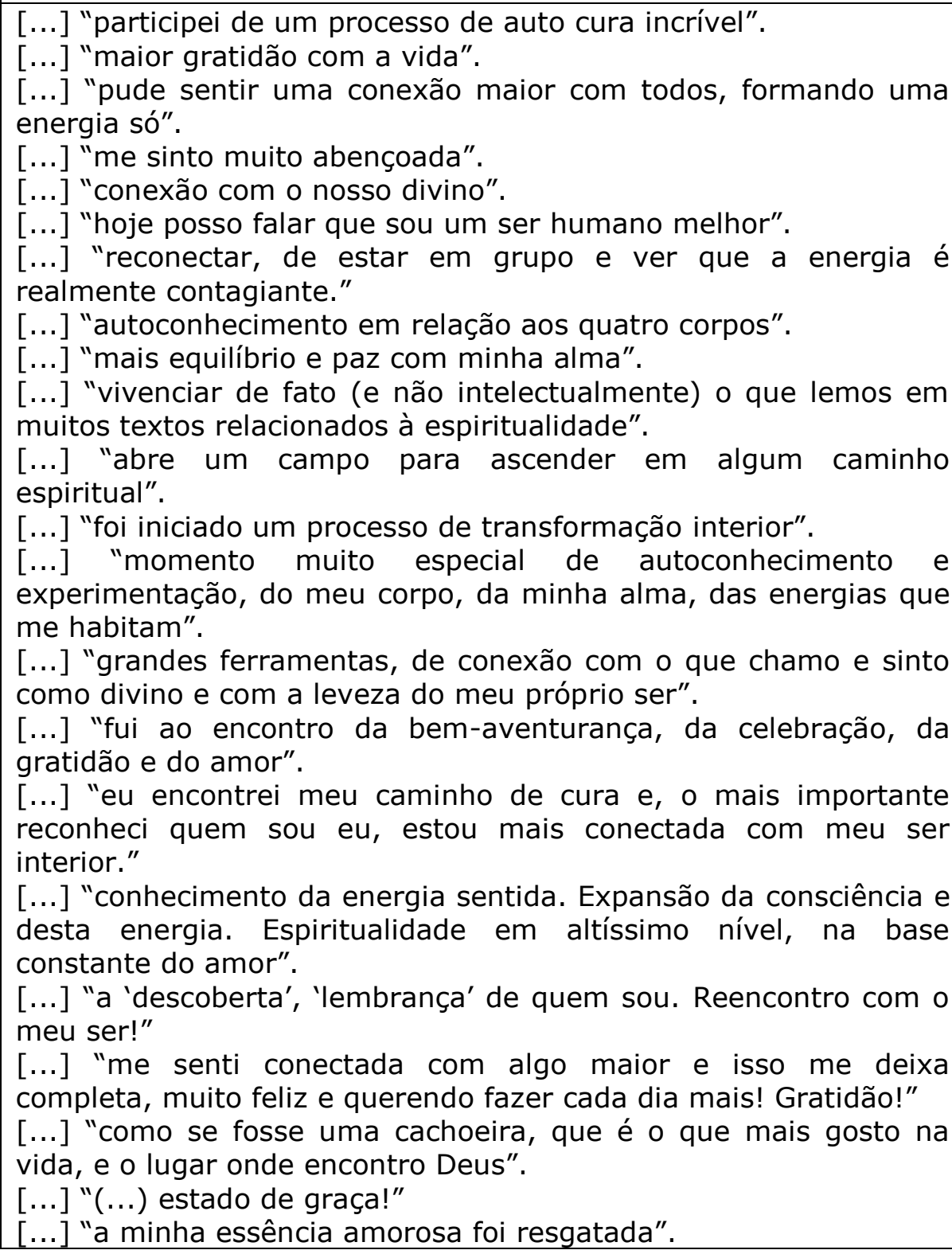 \\
\hline
\end{tabular}

$\mathrm{Na}$ categoria "Físico-Energético" pode-se verificar o quanto a Meditação Ativa de Osho auxilia no "desbloqueio" das tensões acumuladas no corpo, no alívio das dores, no reequilíbrio da energia vital, proporcionando bem-estar, disposição e ânimo. Embora com técnicas diferentes, outras pesquisas mostram resultados semelhantes, indicando que 
através da meditação é possível: aumento do relaxamento físico e mental ${ }^{16}$; diminuição do sintoma da dor na síndrome fibromiálgica ${ }^{17} \mathrm{e}$; aumento do bem-estar geral ${ }^{18-}$ 20. Conforme demonstram os exemplos (trechos da pesquisa de opinião), a seguir:

[...] "sinto menos dor! Consegui aliviar tensões acumuladas no meu corpo".

[...] "acessar e manter um nível de energia e disposição mais elevado."

[...] "diminuição das dores no corpo".

[...] "me senti mais bem-disposta".

[...] "meu corpo está mais leve, livre, a energia circula, está viva".

$\mathrm{Na}$ categoria "Mental" destacamos a eficácia do método que se propõe a criar o contraste entre movimento e silêncio para atingir o estado meditativo, proporcionando maior estado de relaxamento e estados de "não-mente". Houve relatos destacando, também maior facilidade e aderência à prática da meditação ativa, do que com os métodos de 'meditação passivos'. Foi relatado ainda, o aumento da atenção, concentração e foco, colaborando para estar mais presente no "aqui-agora". A meditação dinâmica mostrou-se eficaz para a integração de personalidade, autonomia e domínio ambiental ${ }^{21}$. Outro estudo com a mesma técnica mostrou redução significativa nos níveis plasmáticos de cortisol, quando os participantes foram testados após 21 dias de meditação; concluindo que meditação dinâmica de Osho pode ser recomendada para melhorar o estresse e os distúrbios físicos e mentais 
relacionados ao estresse $\mathrm{e}^{13}$. Nossos achados convergem a esses estudos, com os seguintes trechos:

[...] "mais clareza e foco para a solução de problemas".

[...] "maior concentração. Capacidade de focar no momento presente".

[...] "há mais de dez anos que tenho insônia. Agora consigo dormir sem nenhum problema."

[...] "facilita acalmar a mente e perceber a nãomente de uma forma bem mais fácil do que apenas sentar e meditar (zen)."

[...] "aprendi a relaxar e ficar livre de pensamentos."

Na categoria denominada "Emocional", verificamos que muitos relatos estão associados a uma significativa melhora no estado emocional, com a diminuição da ansiedade, a identificação e aceitação das próprias emoções e sentimentos, obtendo mais 'centramento', alegria, força interior, vontade de viver e autoconfiança.

Esses achados corroboram aos resultados encontrados em estudos anteriores que observaram que a prática da meditação ativa de Osho causou diminuição em vários estados psicopatológicos, como comportamento agressivo e depressão $0^{12}$; melhora da ansiedade ${ }^{12,22}$. Observou-se, ainda melhora do manejo de estresse. O mecanismo de ação foi atribuído principalmente à liberação de emoções reprimidas, inibições e ou traumas psicológicos ${ }^{13}$. Quais sejam:

[...] "diminuição da ansiedade, mais serenidade, tranquilidade, leveza".

[...] "decidi não tomar mais remédios (com aval da psiquiatra) e me senti muito bem". 
[...] "jornada de muita alegria e autoconhecimento. São ciclos de altos e baixos que, no final eu aprendo a me entender melhor".

[...] "menos intempestivo, mais tranquilidade na tomada de decisões, mais segurança, mais alegre".

[...] "fiquei mais calma, mais centrada e sinto que consigo me acolher."

[...] "proporcionou uma dose maior de autoconhecimento e ferramentas para lidar com algumas situações como raiva, estresse, falta de energia".

[...] "me sinto mais segura, minhas preocupações diminuíram e, me sinto mais otimista de um modo geral".

[...] "me sinto mais tolerante e paciente com as pessoas e com os problemas da vida".

[...] "me abri mais para o sentir e não só para o pensar".

[...] "maior equilíbrio e diminuição da ansiedade".

[...] "senti mais ânimo e força para enfrentar a batalha do dia a dia".

[...] "descobri que existe muita coisa bonita dentro de mim".

É de suma importância a conexão com os próprios sentimentos e emoções, assim como, a necessidade de experimentar a livre expressão, a não repressão, o que proporciona uma 'limpeza emocional' e, pode facilitar a 'ampliação da consciência', o aumento do equilíbrio emocional que permite ser mais tolerante consigo mesmo e, com os outros ${ }^{2}$. Lidar melhor com as emoções, reflete diretamente em melhorias nas relações interpessoais e na tomada de decisão ${ }^{23,24}$.

A não identificação e o não julgamento foram bastante citados nos depoimentos, pode-se inferir que isto pode promover mais liberdade, mais espontaneidade e 
autenticidade que colaboram para o fortalecimento da identidade de ser e estar no mundo ${ }^{25}$.

Um benefício na prática da meditação está em 'quebrar o circuito repetitivo de ameaça-excitação-ameaça', pois, aquele que medita relaxa mais facilmente após experimentar algo desafiador. Isto possibilita com que a chance de ver situações inofensivas como ameaçadoras, diminua. O 'meditador' consegue ter a percepção da ameaça com maior exatidão e, então reagir com excitação apenas quando necessário. Mesmo quando acionado, sua recuperação rápida permite com que seja menos provável que reaja como se estivesse sob ameaça do que uma pessoa ansiosa ${ }^{11}$.

E, na última categoria analisada, a "Espiritual", relatamos as possíveis experiências de acesso e abertura a novos níveis de 'expansão da consciência', que podem ampliar o poder de auto cura e a reconexão espiritual. A espiritualidade reconhecida como uma necessidade do ser humano de buscar significado para a existência por meio de conceitos que transcendem o palpável: um sentido de conexão com algo maior que si próprio, que pode ou não estar associado a uma prática religiosa formal ${ }^{26,27}$.

O caminho que Osho propõe como método, iniciando a prática pelo corpo, pode ampliar a consciência, relaxar a mente integrando ao coração, possibilitando a reconexão com o sagrado ${ }^{9}$. Seguem os trechos da pesquisa: incrível".

[...] "participei de um processo de auto cura

[...] "conexão com o nosso divino". 
[...] "me sinto muito abençoada". corpos".

[...] "autoconhecimento em relação aos quatro

[...] "abre um campo para ascender em algum caminho espiritual".

[...] "grandes ferramentas, de conexão com o que chamo e sinto como divino e com a leveza do meu próprio ser".

[...] "eu encontrei meu caminho de cura e, o mais importante reconheci quem eu sou, senti o meu Eu interior e reacendi a compaixão e o amor ao próximo dentro de mim".

[...] "foi realmente libertador e curativo".

Identificamos também, o relato de sensações de pertencimento, de auto realização, de 'reconexão com a essência interior' que pode facilitar o "religare", o contato com o 'Propósito Maior'. Para Baumeister e Leary, os seres humanos têm uma necessidade básica por pertencimento, isto motiva a busca por relações sociais saudáveis e profundas. Enquanto, a não satisfação desta necessidade está fortemente relacionada as consequências prejudiciais psicofisiológicas $^{28}$. Quais sejam:

[...] "sinto um êxtase com tudo, só por estar viva. Aprendi a relaxar, estou livre, tudo flui imensamente e isso basta".

[...] "fui ao encontro da bem-aventurança, da celebração, da gratidão e do amor".

[...] "mais equilíbrio e paz com minha alma".

[...] "estar mais conectada com meu ser interior.

[...] "foi como um chamado para mim".

[...] "me senti conectada com algo maior e isso me deixa completa, muito feliz e querendo fazer cada dia mais! Gratidão! ". 
Também encontramos ênfase na redescoberta do amor consigo, com o outro e com o mundo, trazendo o contato com a sensação de unidade. Como:

[...] "o 'estar presente', que fortaleceu minha relação com o ambiente, com as pessoas e com 0 mundo".

[...] "mais liberdade na minha relação com o mundo".

[...] "pude sentir uma conexão maior com todos, formando uma energia só".

[...] "olhar para as situações do ponto de vista do todo, não do individual".

[...] "conhecimento da energia sentida. Expansão da consciência e desta energia. Espiritualidade em altíssimo nível, na base constante do amor".

[...] "um mergulho para dentro de si que traz o amor como resultado".

[...] "como se fosse uma cachoeira, que é o que mais gosto na vida, e o lugar onde encontro Deus".

[...] "A minha essência amorosa foi resgatada".

Sendo assim, podemos identificar convergência da Meditação Ativa de Osho com a epistemologia dos Cuidados Integrativos. "Novo paradigma" que associa conhecimentos orientais milenares e gregos arcaicos, sabedoria de povos nativos e avanços tecnocientíficos ocidentais modernos promovendo a interface entre, além e através dos eixos "Saúde e Educação"; visando cuidar de toda a natureza em geral, onde está incluso, faz parte a natureza humana em toda a sua multidimensionalidade; onde a totalidade é manifesta no ato de cuidar com amor, compaixão e paz ${ }^{29}$.

Das categorias principais temáticas extraímos as categorias autoconhecimento, alteridade, transdisciplinaridade. 
No que tange ao autoconhecimento, a Meditação Ativa de Osho pode ampliar a consciência e melhorar a saúde de modo integrativo, proporcionando maior conhecimento de si mesmo. Pela perspectiva dos Cuidados Integrativos, o autoconhecimento se dá pela maneira saudável pela qual reconhece e utiliza o corpo na relação consigo mesmo e como instrumento relacional com o mundo, a consciência ampliada, e o religare genuíno (reconhecer como verdade absoluta a presença do sagrado na vida, o caminho pessoal de transcendência) ${ }^{29}$. Por exemplo:

[...] "fiquei mais paciente, mais presente, me conheço muito melhor".

[...] "momento muito especial de autoconhecimento e experimentação, do meu corpo, da minha alma, das energias que me habitam".

[...] "lugar de 'encontro comigo mesma'...".

Observou-se nos depoimentos, o estímulo ao exercício da alteridade (sujeito com o outro), que pode ser entendida como aceitação às diferenças interpessoais, interespécimes, interobjetais, interambientais, sejam nos âmbitos transsócioeconômico, transcultural

e/ou transreligioso/filosófico"29.

A proposta da meditação ativa ter sido também praticada em grupo, contribuiu para estabelecer novas maneiras de vínculo positivo entre os praticantes. a inclusão e aceitação das diferenças, melhorando a interação nas relações como o outro auxiliou, também a motivar e expandir a 'energia', alicerçando o crescimento e o despertar do cuidado de modo integrado. Como: 
[...] "o 'estar presente', que fortaleceu minha relação com o ambiente, com as pessoas e com 0 mundo".

[...] "sinto meu chacra cardíaco muito mais aberto. Me liguei realmente de coração com as pessoas".

[...] "tratar do que cada um acredita sem ferir quem é de outras religiões".

[...] "consigo hoje ser amoroso, ter compaixão pelo próximo, enxergar o lado bom de cada um e, principalmente não julgar".

[...] "estar em grupo e ver que a energia é realmente contagiante."

[...] "é uma forma de mudar os hábitos para cuidar de si mesmo e dos outros".

[...] "gostei muito da sensação de sentir o afeto das pessoas que não conhecia. Acredito que tenha sido o primeiro contato com o sentimento de gratidão".

Quanto ao pilar da Transdisciplinaridade, observou-se que a Meditação Ativa de Osho contribui para a formação do ser humano mais integrado, com olhar mais afetivo consigo mesmo, com o outro e com o mundo. "Pode-se inferir, então, que atitude transdisciplinar consiste na capacidade individual (garante uma afetividade crescente que assegura a ligação entre nós e nós mesmos) ou social (garante uma efetividade crescente de ação no mundo e na coletividade) para manter uma orientação constante e focada, em qualquer que seja a complexidade de uma situação e dos 'acasos' da vida. Assim, a harmonização entre o espaço exterior da efetividade e o espaço interior da afetividade promove o acordo entre Sujeito e o Objeto Transdisciplinares" ${ }^{29}$. Vejamos: melhor".

[...] "hoje posso falar que sou um ser humano

[...] "confiança em mim mesma e no universo". 
[...] "senti um sentimento de autonomia e liberdade bem grande. Não só no corpo, mas na minha maneira de me relacionar com o mundo e com as pessoas".

A meditação ativa de Osho através de sua abordagem sistêmica e sua metodologia vivencial contribuiu para o aumento e promoção da saúde de modo integral, corroborando também ao novo paradigma de saúdeeducação dos Cuidados Integrativos"... seja em relação ao aprendizado de Cuidar de Si, do outro e do planeta, que tem, como referencial o paradigma 'Salutogênico' (foco na habilidade e não na deficiência); utiliza-se operacionalmente do 'Senso de Coerência' (habilidades de mobilizar recursos da força, resistência ou potência, capacidade de enfrentamento ou 'coping' mediante situações adversas inerentes à vida) e; comunga a ideia de que 'ninguém cura - cure ninguém', de que 'todos podem ser apenas facilitadores, ou, infelizmente inibidores do processo de cura - cure do outro', e de que 'somente você tem o poder de curar a si mesmo" ${ }^{29}$.

\section{CONCLUSÃO}

A Meditação Ativa de Osho está ancorada na visão salutogênica congruente com o paradigma em saúdeeducação da epistemologia dos Cuidados Integrativos, que reforça "a cura que vem de dentro".

A partir desse relato de experiências apresentado, podemos inferir efeitos positivos e significativa 
contribuição, desta prática meditativa como agente mobilizador de 'transformação do ser'.

A metodologia proposta por Osho, baseada na vivência permite aos praticantes acessar 'novos estados' de consciência, potencializando o autoconhecimento, promovendo a saúde e contribuindo para um ser humano mais integrado, criativo e 'conectado com o seu coração'.

Observamos o aumento do nível de saúde e bem-estar físico, mental, emocional e espiritual dos praticantes e melhoras significativas no modo de se relacionar consigo, com o outro e com o mundo. Além dos benefícios que podemos alcançar com a meditação, é imprescindível lembrar que a meditação é um estilo de viver e que a prática vai além do que podemos relatar.

Embora a prática da meditação ativa promova inúmeros benefícios à saúde, a sua essência é transcendente. A Meditação Ativa promove o "religare", possibilitando o caminho de reconexão espiritual. Os praticantes podem reconectar com a sua essência, com o amor e a compaixão. Valores estes que são reconhecidos, compartilhados e, estabelecem uma forma mais harmônica e sensível de ser e estar no mundo. Assim, podemos inferir que, a aplicação da Meditação Ativa de Osho é essencialmente integrativa, podendo ser considerada um autêntico Cuidado Integrativo.

Novas pesquisas são necessárias para contribuir com o arrazoado teórico científico da meditação ativa. 


\section{REFERÊNCIAS}

1.Johnson W. Do Xamanismo à Ciência: Uma História da Meditação. São Paulo: Cultrix; 1982.

2.Osho International Foundation. Meditação: primeira e última liberdade. Rio de Janeiro: GMT; 2007.

3.Osho International Foundation. Autobiografia de um Místico Espiritualmente Incorreto. São Paulo: Pensamento-Cultrix; 2000.

4.Rajneesh BS. O Livro dos Segredos. Trad. de CRS Montenegro (Ma Mohani). Volume 1. São Paulo: Maha Lakshmi; 1982.

5.Cardoso R, Souza E, Camano L, Leite JR. Meditation in health: an operational definition. Brain Res Protoc 2004;14:58-60. https://doi.org/10.1016/j.brainresprot.2004.09.002

6.Danucalov MAD, Simões RS. Neurofisiologia da meditação. São Paulo: Phorte; 2006.

7.Rajneesh BS. O livro dos segredos: a ciência da meditação: uma abordagem contemporânea para as 112 meditações descritas no Vigyan Bhairav Tantra/Osho. São Paulo: Ícone; 2009.

8. Osho International Foundation. O livro da Cura: da medicação para a meditação. São Paulo: Shanti;1998.

9.Rajneesh BS. O Livro Orange. São Paulo: Soma Arte; 1982.

10.Osho. Aprendendo a silenciar a mente. Rio de Janeiro: Sextante; 2002.

11.Goleman D. A Mente Meditativa. 4 ed. São Paulo: Ática; 1997.

12.Vyas A. Effects of seven-day osho dynamic study: A pilot study. In: Kostas AF (ed). Psychological Science: Research, Theory and Future Directions. 2007; p.1-19.

13.Bansal A, Mittal A, Seth V. Osho Dynamic Meditation's Effect on Serum Cortisol Level. J Clin Diagn Res 2016;10:CC05-8. https://doi.org/10.7860/JCDR/2016/23492.8827

14.Bardin L. Análise de Conteúdo. Lisboa: Edições 70; 1977.

15. Hochmüller CB (Dayita). Meditação Ativa de Osho sob à luz dos Cuidados Integrativos: relato de experiências. [Monografia]. São Paulo: UNIFESP; 2015.

16.Canter $P$. The therapeutic effects of meditation: the conditions treated are stress related, and the evidence is weak. British Med J 2003;326:1049-50. https://doi.org/10.1136/bmj.326.7398.1049

17. Kozasa EH, Tanaka LH, Monson C, Little S, Leao FC, Peres MP. The effects of meditation-based interventions on the treatment of fibromyalgia. Curr Pain Headache Rep 2012;16:383-7. https://doi.org/10.1007/s11916-012-0285-8

18.Baer RA. Measuring Mindfulness. Contemporary Buddhism 2011;12:241-61. https://doi.org/10.1080/14639947.2011.564842

19.Farb N, Daubenmier J, Price C, Gard T, Kerr C, Barnaby D, et al. Interoception, contemplative practice, and health. Front Psychol 2015;6:763. https://doi.org/10.3389/fpsyg.2015.00763

20.Tang YY. Mechanism of Integrative Body-Mind Training. Neurosci Bull 2011;27:383-8. https://doi.org/10.1007/s12264-011-1141-2 
21.Iqbal N, Singh A, Aleem S. Effect of dynamic meditation on mental health. J Relig Health 2014;5:909-12. https://doi.org/10.1007/s10943-015-0082-x

22.Iqbal N, Singh A, Aleem S, Bano S. Effects of Dynamic Meditation on Anxiety. Indian J Health Wellbeing 2014;5:909-91.

23. Mehling W, Wrubel J, Daubenmier J, Price C, Kerr C, Silow T, et al. Body Awareness: a phenomenological inquiry into the common ground of mind-body therapies. Philos Ethics Humanit Med 2011;6:6. https://doi.org/10.1186/1747-5341-6-6

24.Damásio AR. O erro de Descartes: emoção, razão e o cérebro humano. São Paulo: Companhia das Letras; 2012.

25.Kabat-Zinn J. Mindfulness-based interventions in context: Past, present, and future. Clin Psychol Sci Practice 2003;10:144-56. https://doi.org/10.1093/clipsy.bpg016

26.Saad M, Masiero D, Battistella L. Espiritualidade baseada em evidências. Acta Fisiátric 2001;8:107-12.

https://doi.org/10.5935/0104-7795.20010003

27.Volcan SMA. Relationship between spiritual well-being and minor psychiatric disorders: a cross-sectional study. Rev Saúde Públ 2003;37:440-5. https://doi.org/10.1590/s0034-89102003000400008 28. Baumeister RF, Leary MR. The need to belong: Desire for interpersonal attachments as a fundamental human motivation. Psychol Bull 1995;117:497-529.

29. Fontes SV. Cuidados Integrativos: interface entre saúde transdimensional e educação transdisciplinar [Monografia]. São Paulo: UNIFESP; 2011. 